\title{
Insemination and fertilization in the seed bug Lygaeus simulans (Heteroptera: Lygaeidae)
}

\author{
THOMAS MICHOLITSCH, Peter KRÜGEL and GÜNTHER PASS
} Institute of Zoology, Department of Evolutionary Biology, University of Vienna, Althanstrasse 14, A-1090 Wien, Austria;
e-mail: Thomas.Micholitsch@bmf.gv.at

Key words. Heteroptera, Lygaeus simulans, genitalia, copulation, cryptic female choice, sperm utilization, spermatheca, aedeagus, processus gonophori, insemination, fertilization

\begin{abstract}
In the laboratory, not all females of the seed bug Lygaeus simulans Deckert, 1985, produced fertilized eggs after copulation: $26.7 \%$ of the females were not inseminated and $5 \%$ were inseminated but did not lay fertilized eggs; only in $40 \%$ of the couples did copulation result in fertile eggs. The remaining $28.3 \%$ of couples refrained from mating. Duration of copulation was associated with insemination and fertilization: (i) fertile eggs were produced by only one couple that copulated for less than 60 min and all those that copulated for more than $360 \mathrm{~min}$, (ii) probability of fertilization increased steadily with duration of copulation between 60 and $360 \mathrm{~min}$, and (iii) duration of copulation was significantly different for couples that showed different insemination status.

A possible morphological explanation for this time dependency was revealed by examining the genitalia of 69 couples freezefixed in copula after different periods in copulation. Because of the intricate structure of the genitalia in $L$. simulans, a male takes a long time to manoeuver its intromittent organ into the narrow insemination duct of the female. Only if completely inserted is the tip of the intromittent organ close enough for successful ejaculation of sperm into the spermatheca. The freeze-fixing experiment revealed that it usually took the male more than $30 \mathrm{~min}$ to locate the entrance to the insemination duct and another 30 min for full penetration. This explains why copulations that lasted less than $60 \mathrm{~min}$ failed, since insemination began only after intromission was complete.
\end{abstract}

The experiments, therefore, indicated that there is a relationship between the complex morphology of the genitalia and the low rates of insemination and fertilization in L. simulans.

\section{INTRODUCTION}

Females of many arthropod species have morphologically complex, tortuous genitalic systems that would appear to make insemination difficult (Eberhard, 1985, 1996). This may enable females to bias insemination rates by hampering the passage of the male's intromittent organ to the spermatheca. In this way, females may prevent insemination by unsuitable males. Females may even exert control after insemination has occurred by preventing the fertilization of eggs with stored sperm (Eberhard, 1993; Rodriguez, 1994; Arnqvist, 1997; Dickinson, 1997). Mechanisms excluding particular males as sires of the offspring have been discussed in the context of cryptic female choice (Eberhard, 1996) and male-female conflicts (Alexander et al., 1997).

In many species of lygaeid seed bugs, a male must completely insert its extremely long processus gonopori (intromittent organ) into the narrow and tortuous ductus receptaculi (insemination duct) of a female in order to reach the receptaculum seminis (spermatheca) and successfully deposit sperm (Ludwig, 1926: Lygaeus sp.; Bonhag \& Wick, 1953: Oncopeltus fasciatus; Gschwentner, 1998: L. simulans). This study of L. simulans describes the mechanics of mating, records the duration of copulation associated with insemination and fertilization, and determines the influence of female genital morphology on the frequency of copulations that result in fertile eggs. The length of time required by a male to properly position its intromittent organ and inseminate a female was also determined.

\section{MATERIAL AND METHODS}

\section{Animals}

L. simulans is widespread throughout Eurasia, often occurring sympatrically with its sibling species L. equestris (Deckert, 1985; Lis, 1988; Gusev \& Tatarnikov, 1991). Animals captured in a patch of steppe vegetation on Mount Hundsheim, Austria, were the progenitors of the culture established in the laboratory in the summer of 1995. Each generation takes about three months. The bugs were kept at a temperature of $28^{\circ} \mathrm{C}$, a photoperiod of $16 \mathrm{~L}: 8 \mathrm{D}$ and supplied with distilled water and peeled sunflower seeds. Only adult bugs that were between two weeks and two months old (the period of highest fecundity), which were reared individually from the last instar stage, were used in the experiments. Two to six days after they were laid, fertile eggs turn from white to red. This change in colour was used to distinguish fertile from infertile eggs. Fertilization success was recorded qualitatively (yes/no), not quantitatively, because either all or none of the eggs laid by a female were fertile. Quite a high percentage of the couples did not mate despite being sexually mature. In most cases, males tried to mate but were rejected by the females. Copulation attempts were not recorded.

When not in use, the male intromittent genitalia are contained within the conspicuous genital capsule at the end of the abdomen of males. The phallus consists of the proximal phallobase and the distal aedeagus, which bears the sclerotized processus gonopori of about $7 \mathrm{~mm}$ length. The ejaculatory duct winds through the phallus and opens at the tip of the processus. Prior to copulation, hemolymph pumped into the phallus causes it to unfold out of the capsule and inflates the aedeagus (cf. Ludwig, 
1926: Figs 6, 8). After mates have assumed the typical tail-totail copulation posture, the phallus penetrates the female genital opening up to the phallobase until the aedeagus with the processus gonopori lies entirely inside the female bursa copulatrix. The narrow female ductus receptaculi originates in the bursa from where it spirals for one and a half turns before reaching the receptaculum seminis, the site of sperm storage (cf. Ludwig, 1926: Figs 28, 29; Bonhag \& Wick, 1953: Fig. 36). The processus tip must locate the small entrance to the ductus in the bursa wall and follow the spiralling conduit until the processus gonopori completely penetrates the ductus receptaculi. Only if thus inserted will the processus tip be sufficiently close to ejaculate sperm into the storage tube of the receptaculum seminis (Ludwig, 1926; Bonhag \& Wick, 1953; Hopp, 1988).

\section{Copulation experiment}

The relation between the duration of copulation and the subsequent rates of insemination and fertilization was determined by allowing each of 120 couples, made up of mates taken at random from the stock of virgin animals, to copulate once in a Petri dish. Couples were observed continuously and duration of copulation recorded. When a couple ceased copulating or failed to mate within two hours, the male was removed from the dish. For the following three weeks, each female's production of fertilized and unfertilized eggs was monitored, after which the females were fixed in $70 \%$ ethanol. Whole mounts of their receptacula seminis were embedded in Euparal and screened for the presence of sperm.

\section{Freeze-fixing experiment}

The relation between duration of copulation and the intromission depth of the processus gonopori inside the female ductus receptaculi was determined using couples in plastic mesh boxes ( $3 \mathrm{~cm} \varnothing, 0.5 \mathrm{~cm}$ high) allowed to copulate for a preset time: 60 couples each were allotted $30 \mathrm{~min}$ of copulation (a duration that previously had never resulted in fertile eggs - see also Fig. 2) and another $60 \mathrm{~min}$ (apparently the minimum duration for successful fertilization of eggs - see also Fig. 2). Half of the females in the $30 \mathrm{~min}$ set and half of those in the $60 \mathrm{~min}$ set were virgin; the other 30 in both sets had already been inseminated before the experiment. After the allocated periods had elapsed, plastic boxes with bugs still engaged in copula were swiftly placed in liquid nitrogen for a few seconds. Those that had not copulated after two hours had elapsed or had separated prematurely were discarded. Boxes with freeze-fixed couples were then placed into a mixture of $70 \%$ ethanol and $3 \%$ acetic acid at $-18^{\circ} \mathrm{C}$ for two weeks. Whole mounts were later produced of the combined male-female genitala and embedded in Euparal. Depth of penetration of the ductus receptaculi by the processus gonopori was recorded and classified.

\section{RESULTS}

\section{Copulation experiment}

Of the 120 virgin couples, 86 mated. They copulated for periods that ranged from $2 \mathrm{~min}$ to $16 \mathrm{~h} 51 \mathrm{~min}$ (mean duration $253.05 \mathrm{~min}, \mathrm{~s}=242.09 \mathrm{~min}$ ); most of the copulations lasted for short periods (Fig. 1). While it was always the male that approached the female and initiated copulation, it was not clear which sex terminated the mating. In general, mates remained motionless during long-lasting copulations and were restless during short copulations. Forty-eight females subsequently laid fertile eggs. The relation between fertilization and duration of copulation is given in Fig. 2: only one copulation that lasted for $<60$

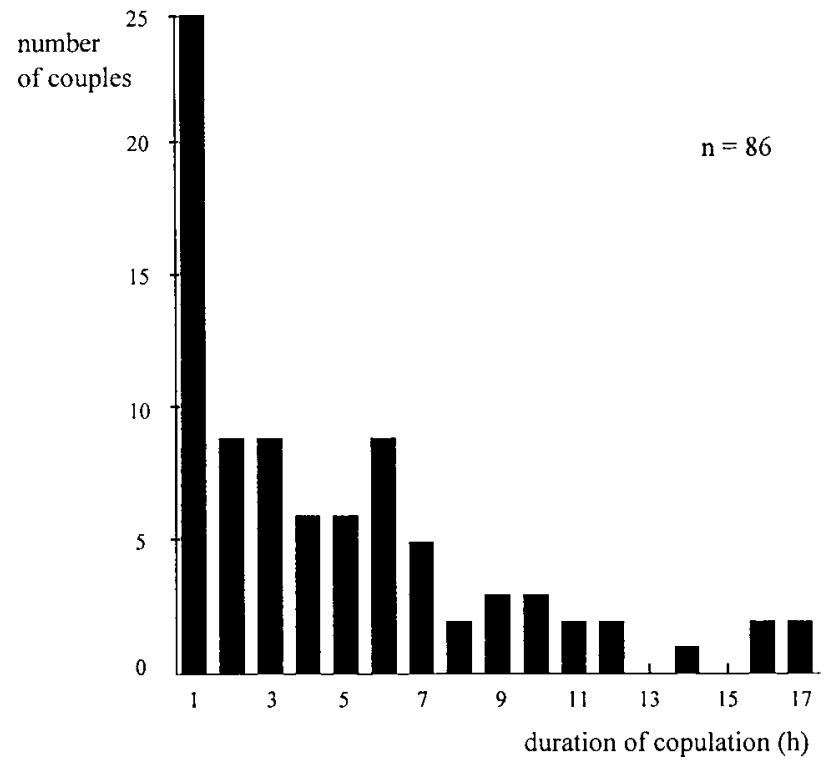

Fig. 1. Duration of copulation in Lygaeus simulans. Duration ranged between $2 \mathrm{~min}$ and $16 \mathrm{~h} 51 \mathrm{~min}$ (mean duration = $253.05 \min , \mathrm{s}=242.09 \min , \mathrm{n}=86$ ).

min and all copulations $\geq 360$ min resulted in fertilization, while in those that lasted between $60 \mathrm{~min}$ and $360 \mathrm{~min}$, the probability of fertilization (sperm present in the receptaculum seminis) increased, the longer the copulation lasted. The duration was significantly longer in those copulations that resulted in fertilization compared to those that did not (Kruskal-Wallis Test, $\chi^{2}=45.48$, df $=1, p<$ $0.0001)$. A logistic regression model was fitted to the data and gave a better fit than the null model at the $\mathrm{p}<0.0002$ level (Chi-Square Test); probability of fertilization was negligible following copulations lasting less than $60 \mathrm{~min}$ and high for those that lasted more than $250 \mathrm{~min}$ (Fig. 3).

In 32 of the 86 mated females, there was no sperm in the receptacula seminis. In a further 6 females, copulation resulted in insemination but not in fertilization. The remaining 48 females laid fertilized eggs. Therefore, lack of fertilization can be due to either copulation fails to result in insemination ( $37 \%$ of the females) or insemination fails to result in fertilization ( $7 \%$ of the females).

Duration of copulation differed significantly between the three categories of couples (Kruskal-Wallis Test, $\chi^{2}=$ $51.14, \mathrm{df}=2, \mathrm{p}<0.0001)$. Multiple comparisons showed that the duration of copulation for the 32 non-inseminated females was significantly different from that for the 48 fertile females (Mann-Whitney Test, two-tailed, $p<$ 0.0001 ); in addition, that for the 32 non-inseminated females was significantly different from that for the 6 inseminated but infertile females (Mann-Whitney Test, two-tailed, $\mathrm{p}<0.008$ ). However, the duration of copulation for the 6 inseminated but infertile females was not significantly different from that for the 48 fertile females (Mann-Whitney Test, two-tailed, $p>0.0125$ ). Since four simultaneous comparisons were made on the same data, the significance level was adjusted to a testwise error of $\alpha^{\prime \prime}=0.0125$, according to the Bonferroni method (Sokal $\&$ Rohlf, 1995). 


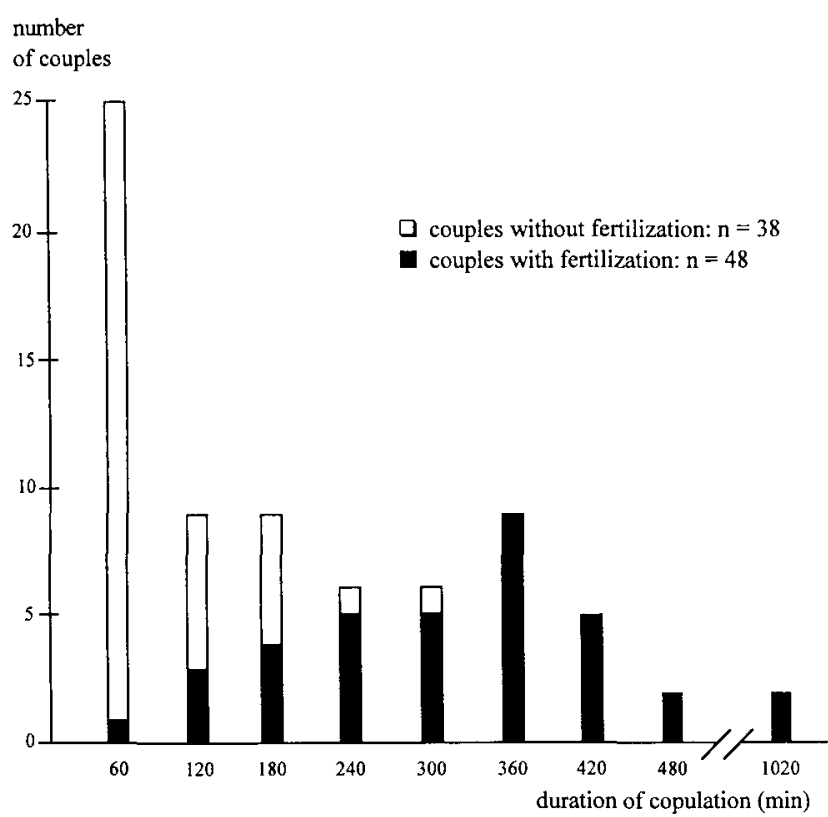

Fig. 2. Duration of copulation and fertilization in Lygaeus simulans. Duration was significantly longer in copulations that resulted in fertilization (Kruskal-Wallis Test, $\chi^{2}=45.48, \mathrm{df}=1$, $\mathrm{p}<0.0001)$

\section{Freeze-fixing experiment}

Whole mount preparations of the male-female genitalia complexes of pairs in copula showed that the long ductus receptaculi is separated from the receptaculum seminis by a bell-shaped widening with a pore at its center (Fig. 6). This access pore into the receptaculum looks like a valve; however, it was not possible to determine whether sperm was stored only on one side of the valve. The receptaculum seminis consists of two sections: proximally, a short, translucent conduit of four to five tight spirals just after the access pore; distally, a conspicuously large, highly contorted, cuticularized sperm storage tube (Figs 4-7). The anatomy of the spirals effectively and consistently prevents any direct contact between the processus gonopori and the sperm storage tube: the spirals are apparently too tightly-wound for the processus to manoeuver through them; reversal of the direction of the coils after each spiral (Fig. 6) is a further obstruction. While the processus tip sometimes penetrated past the first and second spiral, it never extended past the third (Figs 4-7). Consequently, the processus ejaculates sperm into the receptaculum storage tube from the access pore or the spiral. Single sperm cells measure $\sim 100 \mu \mathrm{m}$ in length and less than $5 \mu \mathrm{m}$ in diameter; they lack discernible head and tail regions. Typically, sperm strands consist of several dozen parallelly oriented cells. The storage tube of a female can be entirely crammed with strands, even after a single copulation.

The depths to which the processus gonopori penetrated female genitalia after copulations lasting between 30 and $60 \mathrm{~min}$ were recorded.

Out of the 30 couples in each treatment, 16 copulated in the " $30 \mathrm{~min}$ - virgin females" group, 18 in the "60 min virgin females" group, 18 in the " $30 \mathrm{~min}$ - non-virgin females" group and 17 in the "60 min - non-virgin

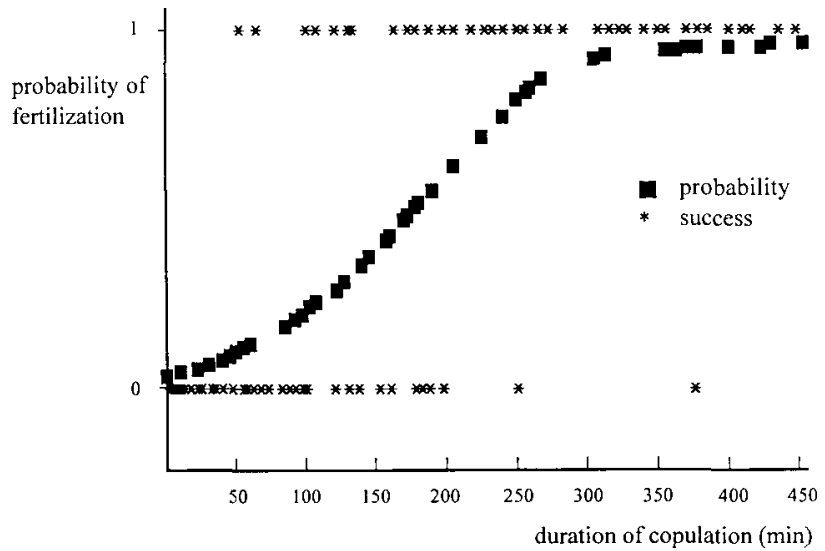

Fig. 3. Duration of copulation and probability of fertilization in Lygaeus simulans. Probability relative to the duration of copulation expressed as a logistic regression model fitted to the data from Fig. 2; the regression model gave a significantly better fit to the data than the null model $(p<0.0002$ level; ChiSquare Test).

females" group. Whole mount preparations disclosed a discrepancy between external and internal coupling of the genitalia. External coupling was complete when the parameres of the male had seized the ovipositor, the phallus had penetrated the female genital opening up to the phallobase and the mates had assumed the tail-to-tail copulation posture. However, in many couples freeze-fixed at this stage, intromission of the processus gonopori into the ductus receptaculi (internal coupling) had not occurred. Even when the processus gonopori entered the ductus, the proximity of its tip to the receptaculum seminis at the time of freeze-fixing was highly variable (Figs 4-7). Five insertion depths (IDs) were distinguished:

ID 0: the processus gonopori had not entered the ductus receptaculi in the allocated time. No whole mounts could be produced because ID 0 does not result in internal coupling of the genitalia: the processi slipped out of the bursae during dissection. That is, apart from intromission into the bursa copulatrix, copulation does not necessarily entail internal coupling.

ID 1: the processus gonopori barely entered the ductus receptaculi (Fig. 4). ID 2: the processus tip reached midway into the ductus and was equidistant from the bursa and the access pore at the instant of freeze-fixing (Fig. 5). ID 3: the processus tip reached the end of the ductus and lay within the bell-shaped widening of the access pore (Fig. 6). ID 4: the processus tip had entered the access pore and reached the first, second or third turn of the spiral (Fig. 7). Even in the case of a shallow penetration, such as ID 1, contact between the genitalia remained firm from the time of freeze-fixing until dissection so the position of the processus inside the ductus could be accurately determined.

The 30 min copulations with virgin females resulted in the largest number of ID 0 cases (non-intromission into the ductus receptaculi) and the smallest number of ID 4 cases (deepest penetration). The 60 min copulations with non-virgin females, in contrast, resulted in the smallest 


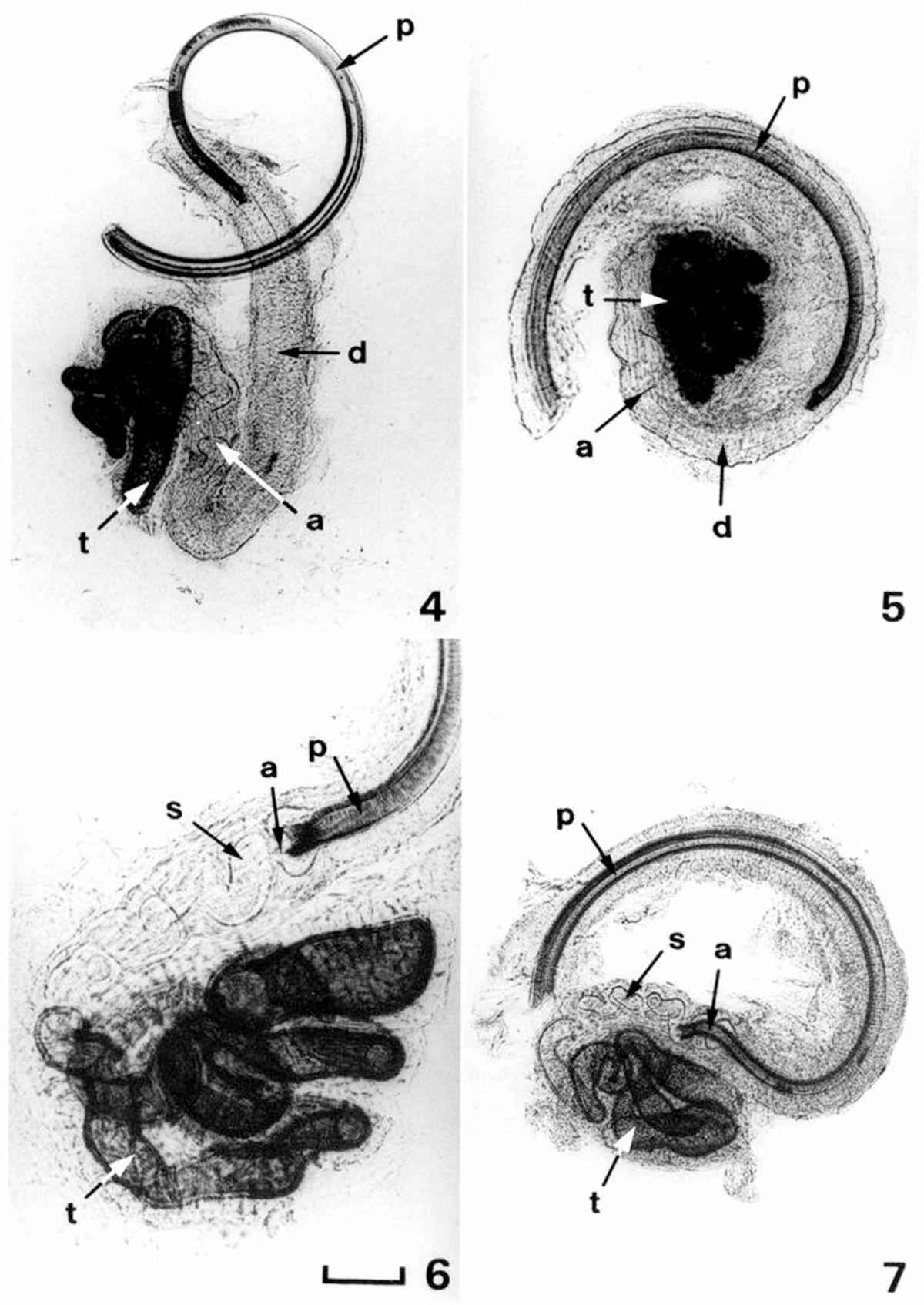

Figs 4-7: Lygaeus simulans. Depth of penetration into the female genitalia by the male intromittent organ; processus gonopori proximally cut off. 4 - processus gonopori barely inside ductus receptaculi (cf. ID 1); 5 - processus midway in ductus (cf. ID 2); 6 processus tip at access pore (cf. ID 3); 7 - processus past access pore in spiral (cf. ID 4). For frequencies of IDs see Table 1. Abbreviations: $\mathrm{a}=$ access pore, $\mathrm{d}=$ ductus receptaculi, $\mathrm{p}=$ processus gonopori, $\mathrm{s}=$ spiral of the receptaculum seminis, $\mathrm{t}=$ sperm storage tube of the receptaculum seminis. Scale bars: $0.4 \mathrm{~mm}(4,5,7) ; 0.16 \mathrm{~mm}(6)$.

number of ID 0 cases and the highest number of ID 4 cases (Table 1).

TABLE 1. Lygaeus simulans, five classes of intromission depth (ID $0-$ ID 4 ) of the male intromittent organ within the female genitalia.

\begin{tabular}{lccccc}
\hline & ID 0 & ID 1 & ID 2 & ID 3 & ID 4 \\
\hline virgin 30 min & 9 & 4 & 0 & 1 & 2 \\
virgin 60 min & 4 & 2 & 3 & 2 & 7 \\
non-virgin 30 min & 3 & 1 & 3 & 2 & 9 \\
non-virgin 60 min & 1 & 0 & 3 & 2 & 11 \\
\hline
\end{tabular}

The relation between depth of penetration and duration of copulation ( 30 or $60 \mathrm{~min}$ ) on the one hand and the virginity status of the females (virgin or non-virgin) on the other, was tested. For this test, only two classes of penetration were used, formed out of the original five ID classes: shallow penetration (ID 0/ID 1) and deep penetration (ID 3/ID 4). Since five simultaneous comparisons were made on the same data, the significance level was adjusted to a testwise error of $\mathrm{a}^{\prime \prime}=0.01$ according to the Bonferroni method. Applying a "Pearson" chi-square test for goodness of fit to the data (Sokal \& Rohlf, 1995) re- 
vealed a non-random distribution of depth of penetrations both in relation with duration of copulation and the virginity status of females (" $\chi^{2 "}=19.63, \mathrm{df}=4, \mathrm{p}<0.0006$ ). Deep penetration was significantly more frequently observed when the duration of copulation was long and with non-virgin females. However, when the data were additionally subjected to four Fisher's exact tests of independence to investigate more closely the relation between penetration depth and duration of copulation and between penetration depth and virginity status, most differences were insignificant. The penetration depth (ID $0 /$ ID 1 as opposed to ID 3/ID 4) recorded for the $30 \mathrm{~min}$ copulations with virgin females differed significantly from that recorded for the $30 \mathrm{~min}$ copulations with non-virgin females (two-tailed, $\mathrm{p}<0.004$ ). It was not significantly different in the $60 \mathrm{~min}$ copulations with virgin females compared with the $60 \mathrm{~min}$ copulations with non-virgin females (two-tailed, $\mathrm{p}>0.01$ ), or in the 30 min copulations with virgin females compared with the 60 min copulations with virgin females (two-tailed, $p>0.01$ ), or in the 30 min copulations with non-virgin females compared with the $60 \mathrm{~min}$ copulations with non-virgin females (two-tailed, $\mathrm{p}>0.01$ ).

Whole mounts of deep/deepest penetration (ID 3/ID 4) often showed that at the instant of freeze-fixing, sperm strands were in the process of being ejaculated out of the processus gonopori tip into the sperm storage tube of the receptaculum seminis. A "Pearson" chi-square test for goodness of fit confirmed that ejaculation was significantly more frequent in the copulations of long duration and in matings involving non-virgin females (" $\chi^{2 "}=21.1$, $\mathrm{df}=3, \mathrm{p}<0.0001$ ).

\section{DISCUSSION}

Lygaeid bugs remain in copula for long and variable periods of time (Ludwig, 1926; Andre, 1934; Hopp, 1988). In L. simulans, the longest copulation lasted for $1011 \mathrm{~min}$ and the mean duration was $253.05 \mathrm{~min}$. Only $4 \%$ of the females that copulated for $\leq 60 \mathrm{~min}$ subsequently produced fertile eggs, whereas $100 \%$ of the females that copulated for $\geq 360 \mathrm{~min}$ did. In addition, the probability of a female being fertile increased steadily with the duration of copulation between 60 and $360 \mathrm{~min}$ (Figs 2-3).

Of the 86 females that mated, only 54 were inseminated. Six of the 54 females did not produce fertile eggs. As the ovaries of these females contained eggs when dissected, it is assumed they refrained from using the stored sperm for egg fertilization. It has been argued that a sperm storage organ and delayed fertilization enables females to accept or reject sperm following insemination and deprives males of direct influence on whether their sperm fertilizes eggs (Fowler, 1973; Gromko et al., 1984; Eberhard, 1996, 1997; Alexander et al., 1997; Brown et al., 1997; Dickinson, 1997). Remarkably, 22 out of the 86 couples copulated for several hours longer than the $6 \mathrm{~h}$ needed for successful fertilization (Fig. 1). According to the cryptic female choice theory, extended copulation may be a strategy used by males to induce females to util- ize their sperm (Thornhill, 1983; Eberhard, 1985, 1996 , 1997). Alternatively, long copulations may serve mateguarding (Alcock, 1994). Although females were only exposed to one male, the mate-guarding hypothesis may still apply, since males may have sensed males in adjacent Petri dishes.

The duration of copulation was associated with whether the females were not inseminated, inseminated but not fertilized or fertilized. This supports the time-dependency of insemination and fertilization. The freeze-fixing experiment revealed that insemination is time-dependent as it takes most males at least $30 \mathrm{~min}$ to locate, with the tip of their processus gonopori (intromittent organ), the entrance to the female ductus receptaculi (insemination duct) inside the bursa copulatrix. Alternatively, searching for the ductus entrance may not be the problem and the male's intromittent organ remains inside the bursa copulatrix for about $30 \mathrm{~min}$ before penetrating the ductus. After this, it takes approximately another $30 \mathrm{~min}$ for the processus to penetrate the ductus, pass the access pore and reach the tightly-wound spiral section of the receptaculum seminis (spermatheca). Only if inserted in this way does the tip of the processus lie close to the storage tube of the receptaculum seminis, into which the sperm is ejaculated (Figs 4-7, Table 1). Insemination is therefore unlikely to occur within the first hour of copulation in L. simulans. Similarly, a previous study on the sibling species $L$. equestris found that matings interrupted after 15, 30 and $60 \mathrm{~min}$ resulted in average fertilization rates of $2 \%$, $17.6 \%$ and $45.9 \%$, respectively. The long copulations $(\geq 15 \mathrm{~h})$ in this species are thought to indicate a male mate-guarding to forestall sperm displacement. When given the choice, the males preferred gravid to virgin females (Sillen-Tullberg, 1981). This is supported by the results from the freeze-fixing experiment: intromission was achieved faster in non-virgin females.

In L. simulans, the proper positioning of the male intromittent organ inside the female insemination duct is a prerequisite for successful sperm transfer (cf. Aedes aegypti: Gwadz et al., 1971; Gwadz, 1972). External coupling of the genitalia is achieved after the parameres of the male have scized the ovipositor, the phallus has penetrated the female genital opening and the aedeagus with the processus gonopori lics entirely inside the bursa copulatrix (Ludwig, 1926; Bonhag \& Wick, 1953). However, the results of the freeze-fixing experiment clearly indicate that external coupling of the genitalia did not necessarily result in the processus gonopori entering the ductus receptaculi (frequency of ID 0; Table 1). If it does, the processus gonopori may only reach the ductus or the access pore separating the ductus from the receptaculum scminis. It is not clear whether incomplete intromission (e.g. ID 1, ID 2) is accompanied by insemination or whether sperm ejaculated into the ductus can eventually reach the sperm storage tube of the receptaculum. In the case of complete intromission and insemination, the tip of the processus reaches the spiral, which prevents it coming into direct contact with the sperm storage tube (frequencies of ID 1 - ID 4; Table 1). Functionally analogous to 
the spiral in L. simulans is the "ampulla" structure that serves the same function in the chrysomelid beetle Chelymorpha alternans (Rodriguez, 1994; Rodriguez, Eberhard \& Windsor, in prep., cited after Eberhard, 1996, pp. 351-353).

The morphologies of the ductus receptaculi and the receptaculum spiral exert a passive control over genital access in L. simulans. In addition, the longitudinal musculature enveloping the spiral and part of the bell-shaped widening that houses the access pore may actively control genital access (Gschwentner, 1998). Such passive and active control exist in various chrysomelid beetles: the spermathecal muscles actively block eversion of male genitalia (Dickinson, 1997) or insemination is passively prevented as the male fails to completely thread its long, thin intromittent organ up the tightly-coiled female spermathecal duct (Rodriguez, 1994).

The structure of the female genitalia (ductus, access pore, spiral) serves as an obstacle to the male's intromittent organ and thus probably biases insemination and fertilization rates. The long and winding insemination duct even continuing into a secondary tortuosity (spiral) before connecting to the remote receptaculum seminis may be a means of controlling the entry of sperm rather than insemination efficiency. Therefore, females of $L$. simulans obviously exert a mechanical cryptic female choice via the morphology of their genitalia.

ACKNOWLEDGEMENTS. Thanks are due to the many students who monitored the seed bugs during copulation. A Tadler contributed numerous suggestions to the design of the study and commented on various stages of the draft, as did B.A. GerebenKrenn and H. Krenn. K.P. Zulka furnished statistical advice. This study was supported by the Austrian Science Foundation (project \# P-10665-BIO).

\section{REFERENCES}

AlCock J. 1994: Postinsemination associations between males and females in insects: The mate-guarding hypothesis. Annu. Rev. Entomol. 39: 1-21.

Alexander R.D., Marsianll D.C. \& Cooley J.R. 1997: Evolutionary perspectives on insect mating. In Choe J.C. \& Crespi B.J. (eds): Mating Systems in Insects and Arachnids. Cambridge University Press, Cambridge, pp. 4-31.

ANDRE F. 1934: Notes on the biology of Oncopeltus fasciatus (Dallas). Iowa St. Coll. J. Sci. 9: 73-87.

ARNQvist G. 1997: The evolution of animal genitalia: distinguishing between hypotheses by single species studies. Biol. J. Linn. Soc. 60: 365-379.

BoniAg P.F. \& WICK J.R. 1953: The functional anatomy of the male and female reproductive systems of the milkweed bug, Oncopeltus fasciatus (Dallas) (Heteroptera: Lygaeidae). $J$. Morphol. 93: 177-283.

Brown W.D., Crespi B.J. \& ChoE J.C. 1997: Sexual conflict and the evolution of mating systems. In Choe J.C. \& Crespi B.J. (eds): Mating Systems in Insects and Arachnids. Cambridge University Press, Cambridge, pp. 352-377.

DECKERT J. 1985: Über Lygaeus simulans spec. nov. und L. equestris (Linnaeus, 1758), zwei nahe verwandte paläarktische Lygaeinae (Heteroptera, Lygaeidae). Mitt. Zool. Mus. Berl. 61: 273-278.
DiCKINSON J.L. 1997: Multiple mating, sperm competition and cryptic female choice in the leaf beetles (Coleoptera: Chrysomelidae). In Choe J.C. \& Crespi B.J. (eds): Mating Systems in Insects and Arachnids. Cambridge University Press, Cambridge, pp. 164-183.

Eberitard W.G. 1985: Sexual Selection and Animal Genitalia. Harvard University Press, Cambridge, MA, 244 pp.

EBERHARD W.G. 1993: Copulatory courtship and genital mechanics of three species of Macrodactylus (Coleoptera, Scarabaeidae, Melolonthinae). Ethol. Ecol. Evol. 5: 19-63.

Eberiand W.G. 1996: Female Control: Sexual Selection by Cryptic Female Choice. Princeton University Press, Princeton, $502 \mathrm{pp}$.

EiscruinRD W.G. 1997: Sexual selection by cryptic female choice in insects and arachnids. In Choe J.C. \& Crespi B.J. (eds): Mating Systems in Insects and Arachnids. Cambridge University Press, Cambridge, pp. 32-57.

FowLER G. 1973: Some aspects of the reproductive biology of Drosophila: Sperm transfer, sperm storage and sperm utilization. Adv. Genet. 17: 293-360.

Gromko M.H., Newport M.E.A. \& Kortier M.G. 1984: Sperm dependence of female receptivity to remating in Drosophila melanogaster. Evolution 38: 1273-1282.

GsCIIWENTNER R. 1998: Funktionsanatomie der weiblichen Genitalien der Ritterwanze Lygaeus simulans (Heteroptera, Lygaeidae). M.Sc. Thesis, University of Innsbruck, $68 \mathrm{pp}$.

Gusev R.V. \& TATARNIKov D.P. 1991: On the distinguishing characters and distribution of the bugs Lygaeus simulans Deckert and L. equestris (Linnaeus) (Heteroptera, Lygaeidae). Rev. Entomol. USSR 70: 404-406.

GWADz R.W. 1972: Neuro-hormonal regulation of sexual receptivity in female Aedes aegypti. J. Insect Physiol. 18: 259-266.

Gwadz R.W., Craig G.B. Jr. \& Hickey W.A. 1971: Female sexual behavior as the mechanism rendering Aedes aegypti refractory to insemination. Biol. Bull. 140: 201-214.

Horp I. 1988: Morphologisch-biologische Untersuchungen an Genitalstrukturen, Flügeln und Vorderbeinen der Lygaeiden (Heteroptera) - Ein Beitrag zur Problematik der Erstellung eines phylogenetischen Systems. Doctoral thesis, University of Freiburg i. Br., $161 \mathrm{pp}$.

Lis J.A. 1988: Nowe stanowiska Lygaeus simulans Deckert, 1985 (Heteroptera, Lygaeidae) w Polsce. (New stations of Lygaeus simulans Deckert, 1985 in Poland.) Przegl. Zool. 32: 207-209 (in Polish, English abstr.).

LuDwIG W. 1926: Untersuchungen über den Copulationsapparat der Baumwanzen. Z. Morphol. Ökol. Tiere 5: 291-380.

Rodriguez V. 1994: Fuentes de variación en la precedencia de espermatozoides de Chelymorpha alternans Boheman 1854 (Coleoptera: Chrysomelidae: Cassidinae). M.Sc. Thesis, Universidad de Costa Rica, $69 \mathrm{pp}$.

Sillén-TUl.lbERg B. 1981: Prolonged copulation: a male "postcopulatory" strategy in a promiscuous species, Lygaeus equestris (Heteroptera: Lygaeidae). Behav. Ecol. Sociobiol. 9: 283-289.

Sokıl R.R. \& RolltF F.J. 1995: Biometry: The Principles and Practice of Statistics in Biological Research. 3rd ed. W.H. Freeman, New York, 887 pp.

THornhill. R. 1983: Cryptic female choice and its implications in the scorpionfly Harpobittacus nigriceps. Am. Nat. 122: $765-788$.

Received March 19, 1999; accepted September 15, 1999 